\title{
Effective Bond Length of FRP Sheets Externally Bonded to Concrete
}

\author{
Mongi Ben Ouezdou ${ }^{1,3)}$, Abdeldjelil Belarbi ${ }^{2)}$, and Sang-Wook Bae ${ }^{2)}$
}

(Received September 8 2008, Revised July 30, 2009, Accepted November 20, 2009)

\begin{abstract}
Strengthening and repair of concrete structures using externally bonded fiber reinforced polymer (FRP) composite sheets has been popular around the world during the last two decades. However, premature failure due to debonding of the FRP is one of the important issues still to be resolved. Numerous research studies have dealt with the debonding problem in terms of Effective Bond Length (EBL), however, determination of this length has not yet been completely assessed. This paper summarizes previous works on the EBL and proposes a new relationship of the EBL with the FRP stiffness based on the existing experimental data collected in this study.
\end{abstract}

Keywords: reinforced concrete, fiber reinforced polymer, debonding, effective bond length.

\section{Introduction}

Strengthening and repair/rehabilitation of concrete structures using externally bonded fiber reinforced polymer (FRP) sheets has demonstrated its effectiveness through many laboratory tests and field applications performed in the last two decades. However, premature failure due to debonding of the FRP sheets does not take advantage of its full effectiveness and may also reduce the level of safety of the strengthened structures. Hence the debonding problem has become a growing concern for both engineers and researchers. Numerous studies have been conducted on this subject in terms of bond strength, bond stress-slip relationship, effective bond length (EBL), and the interfacial fracture energy. The EBL is used to evaluate the bond strength between concrete and FRP and thus the EBL is needed to evaluate the maximum load to be carried by the strengthened structure.

The EBL can be defined as a length over which the majority of the bond stress is maintained. Currently, many design codes/ guidelines/specifications around the world present equations to evaluate the effective bond length. ${ }^{1-8}$ A summary of the EBL, as considered by several codes, is presented in Table 1. Fig.1 presents the EBL versus FRP stiffness $\left(E_{f} t_{f}\right)$ calculated by several code

\footnotetext{
${ }^{1)}$ Civil Engineering Laboratory, National Engineering School of Tunis, BP 37, 1002 Tunis-Belvédère, Tunisia. E-mail: mongi. benouezdou@enit.rnu.tn

${ }^{2)}$ Dept. of Civil, Architectural, and Environmental Engineering, Missouri University of Science and Technology, Rolla, MO 65409-0030, USA.

${ }^{3)}$ Dept. of Civil and Environmental Engineering Department, College of Engineering and Architecture, University of Nizwa, Nizwa, Sultanate of Oman.

Copyright (c) 2009, Korea Concrete Institute. All rights reserved, including the making of copies without the written permission of the copyright proprietors.
}

design equations (refer to Table 1). In this figure, the same material properties were used: a concrete modulus $\left(E_{c}\right)$ corresponding to concrete strength, $\mathrm{f}_{\mathrm{c}}$ of $40 \mathrm{MPa}$, an elastic modulus $\left(E_{f}\right)$ of 72 and $228 \mathrm{GPa}$ for Glass FRP (GFRP) and Carbon FRP (CFRP), respectively, and thicknesses $\left(t_{f}\right)$ of 0.353 and $0.17 \mathrm{~mm}$ for GFRP and CFRP, respectively. As shown in Fig. 1, the EBL is quite different depending on which equations are used for calculations. It was found that some of the code equations typically show a decrease in the EBL with increase in stiffness of the FRP $\left(E_{f} t_{f}\right)$ while others show the exact opposite trend. The main reason for the difference in results can be attributed to the fact that the equations were derived using a very limited experimental data, from which the mechanism involved in the debonding of FRP cannot be completely understood.

In this paper, the existing research on EBL and debonding mechanism are presented along with a simple but practical equation proposed for determining the EBL.

\section{The concept of effective bond length}

Tension in concrete is transferred to FRP sheets mainly through shear stresses in the adhesive in a short length near the applied load. As the load increases, cracking near the applied load shifts the active bond zone to a new area further away from the loading point, indicating that only part of the bond is effective. This part is called the effective bond length (EBL). Hence, the EBL is the active bonding zone along which most of the interfacial stress is transmitted into the concrete. When the bonded length of FRP along the FRP-concrete interface exceeds the EBL no further increase in failure load can be achieved (Fig. 2(a)).

The concept of EBL is also defined through the strain distribution for which the effective bond length is the distance required for the strain to vanish (Fig. 2(b)). The EBL of FRP takes the entire load to a certain level at which localized debonding occurs, caus- 
Table 1 Summary of the effective bond length as specified by various FRP codes.

\begin{tabular}{|c|c|c|c|}
\hline Code & Year & Expression & Reference applied \\
\hline ACI $440.2 \mathrm{R}-02^{1}(U S A)$ & 2002 & $L_{e}=\frac{23300}{\left(n E_{f} t_{f}\right)^{0.58}}$ & Maeda et al. ${ }^{9} L_{e}=e^{6.134-0.58 \ln \left(E_{f} t_{f}\right)}$ \\
\hline ISIS $^{2}$ CSA S806-02 $2^{3}$ (Canada) & 2002 & $L_{e}=\frac{25350}{\left(E_{f} t_{f}\right)^{0.58}}$ & Maeda et al. ${ }^{9} L_{e}=e^{6.134-0.58 \ln \left(E_{f} t_{f}\right)}$ \\
\hline FIB B $14^{4}$-Appendix A1 (Europe) & 2001 & $L_{e}=\sqrt{\frac{E_{f} t_{f}}{c_{2} f_{c t m}}} \quad c_{2}=2$ & Neubauer and Rostásy ${ }^{10} L_{e}=\sqrt{\frac{E_{f} t_{f}}{2 f_{c t m}}}$ \\
\hline FIB B14 - Appendix A2 (Europe) & 2001 & $L_{e}=c_{2} \sqrt{\frac{E_{f} t_{f}}{f_{c k} f_{c t m}}} \quad c_{2}=1.44$ & - \\
\hline $\operatorname{CS} \operatorname{TR}_{55}^{5}(U K)$ & 2004 & $L_{e}=0.7 \sqrt{\frac{E_{f} t_{f}}{f_{c t m}}}$ & Neubauer and Rostásy ${ }^{10} L_{e}=\sqrt{\frac{E_{f} t_{f}}{2 f_{c t m}}}$ \\
\hline CNR-DT 200/04 ${ }^{6}$ (Italy) & 2005 & $L_{e}=\sqrt{\frac{E_{f} t_{f}}{2 f_{c t m}}}$ & FIB- B14 - Apx $\mathrm{A}^{4} L_{e}=\sqrt{\frac{E_{f} t_{f}}{c_{2} f_{c t m}}} \quad c_{2}=2$ \\
\hline Eurocode $8-3^{7}$ (Europe) & 2004 & $L_{e}=\sqrt{\frac{E_{f} t_{f}}{4 f_{c t m}}}$ & 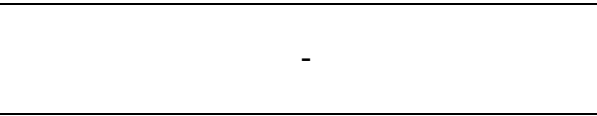 \\
\hline $\operatorname{CIDAR}^{8}($ Australia $)$ & 2006 & $L_{e}=\sqrt{\frac{E_{f} t_{f}}{\sqrt{f_{c}^{\prime}}}}$ & Chen and Teng ${ }^{11} L_{e}=\sqrt{\frac{E_{f} t_{f}}{\sqrt{f_{c}^{\prime}}}}$ \\
\hline
\end{tabular}

$\overline{E_{f}}=$ elastic modulus of FRP, $L_{e}=$ effective bond length, $f_{c}^{\prime}=$ concrete strength, $f_{c k}=$ characteristic strength of concrete, $f_{c t m}=$ mean tensile strength of concrete, $n=$ number of layers of FRP, $t_{f}=$ thickness of FRP, $\tau_{\max }=$ maximum bond strength of FRP onto concrete surface

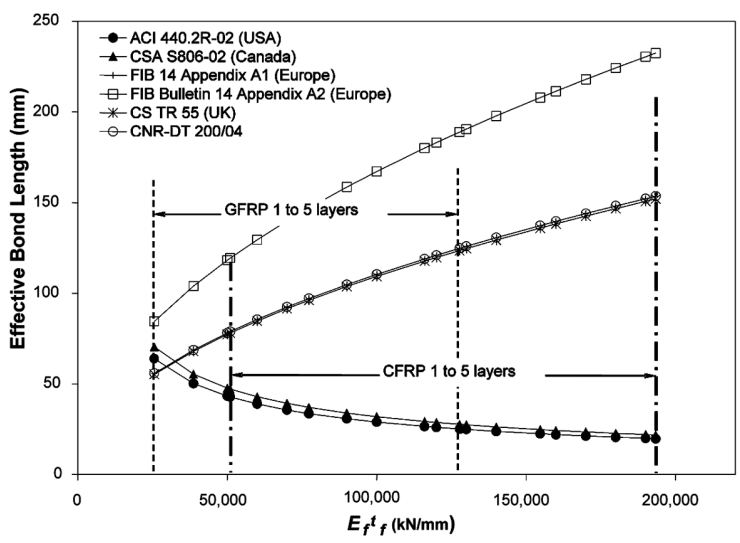

Fig. 1 Effective bond length calculated using the current codes/specifications/guidelines.

ing the EBL to shift to another active bonding zone. This shifting continues until the FRP is completely debonded from the concrete. In other words, when debonding occurs in the vicinity due to fracture of the concrete surface, the active zone is shifted to a new zone. This phenomenon is repeated until debonding propagates completely. At any stage of loading, the EBL is the length at which the FRP resists the entire load through its bond stress. However, it is also important to numerically quantify the EBL. Although extensive research has been conducted to investigate the bond behavior between FRP and concrete, there are no commonly accepted analytical models to predict the EBL as previously discussed and shown in Fig. 1. This issue is further discussed in and a practical model is proposed based on analysis of the data obtained from the published literature.

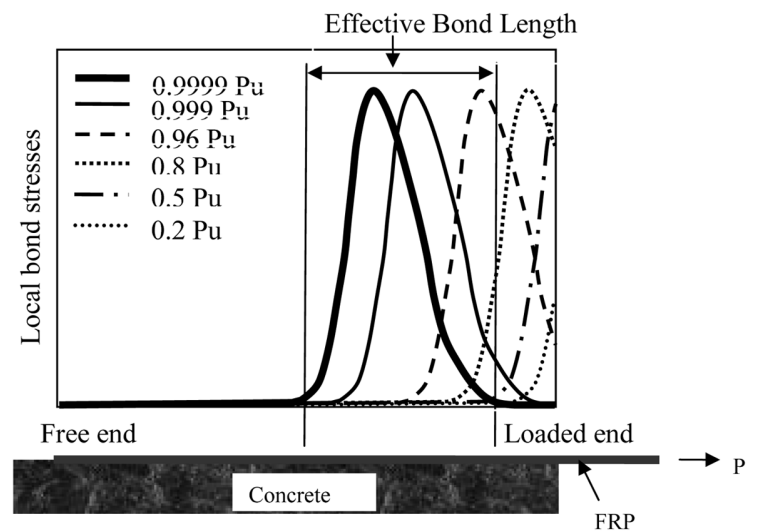

(a)

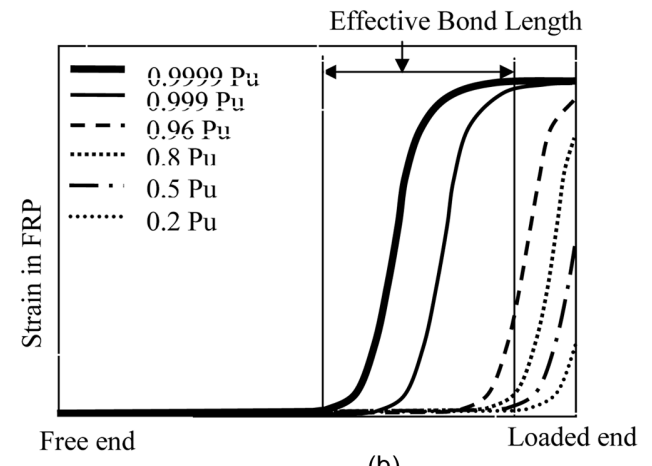

(b)

Fig. 2 Concept of the effective bond length (EBL): (a): in terms of stress distribution (after Ueda and Dai ${ }^{12}$ ); (b) in terms of strain distribution (after Ueda and $\mathrm{Dai}^{13}$ ).

\section{Experimental data on the effective bond length}

The problems associated with debonding of FRP were studied 
through many experimental studies. Various test set-ups were employed to study the bond mechanism of FRP sheets externally bonded to concrete, such as single shear tests, double shear tests, and bending tests. The set-up usually consisted of two concrete elements on which an FRP sheet was adhered (on both sides) and data was taken from strain-gages glued to one side of the FRP in order to obtain graphs similar to those shown in Fig. 2(b).

Data gathered from the literature on experimental studies of EBL has been summarized in Table 2 in terms of concrete strength, elastic modulus of concrete and FRP, as well as thickness of FRP, since it is known from previous research studies that these parameters affect the bond of FRP sheets to concrete surfaces.

\section{Proposed equations to determine the effective bond length}

Data shown in Table 2 was plotted in Fig. 3 in order to deter-

Table 2 Summary of data on the experimental results of the effective bond length $\left(L_{e}\right)$ gathered from literature.

\begin{tabular}{|c|c|c|c|c|c|c|c|}
\hline Reference & Specimen ID & Types of FRP & $f_{c}^{\prime},(\mathrm{MPa})$ & $E_{c},(\mathrm{GPa})$ & $E_{f},(\mathrm{GPa})$ & $t_{f},(\mathrm{~mm})$ & $L_{e},(\mathrm{~mm})$ \\
\hline Sato et al. $^{14}$ & - & 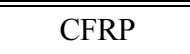 & 3737.6 & 25.5 & 236 & 0.115 & $4 \quad 45.2$ \\
\hline \multirow{4}{*}{$\begin{array}{l}\text { Bizindavyi and } \\
\text { Neale }^{15}\end{array}$} & - & GFRP & \multirow{4}{*}{42.5} & \multirow{4}{*}{33.5} & 29.2 & 1.00 & 75 \\
\hline & - & GFRP & & & 29.2 & 2.00 & 100 \\
\hline & - & CFRP & & & 75.7 & 0.33 & 55 \\
\hline & - & CFRP & & & 75.7 & 0.66 & 70 \\
\hline De Lorenzis et al. ${ }^{16}$ & - & CFRP & 47.3 & $32.5^{* *}$ & 227 & 0.16 & 93 \\
\hline \multirow{11}{*}{ Nakaba et al. ${ }^{17}$} & C5-ARF & Aramid & \multirow{5}{*}{57.6} & \multirow{5}{*}{29} & 124.5 & 0.193 & 65.9 \\
\hline & C5-SCF & CFRP & & & & \multirow{3}{*}{0.167} & 95.7 \\
\hline & C5-SCFL & CFRP & & & 261.1 & & 63.5 \\
\hline & C5-SCFH & CFRP & & & & & 133.5 \\
\hline & C5-HCF & H-CFRP & & & 425.1 & 0.165 & 120.3 \\
\hline & M5-ARF & Aramid & \multirow{5}{*}{47.1} & \multirow{5}{*}{24.5} & 124.5 & 0.193 & 70.3 \\
\hline & M5-SCF & CFRP & & & \multirow{5}{*}{261.1} & \multirow{5}{*}{0.167} & 96.6 \\
\hline & M5-SCFL & CFRP & & & & & 67.0 \\
\hline & M5-SCFH & CFRP & & & & & 134.1 \\
\hline & M5-HCF & H- CFRP & & & & & 121.2 \\
\hline & C2-SCF & CFRP & 23.8 & 22.0 & & & 99.1 \\
\hline \multirow{2}{*}{$\begin{array}{c}\text { Foster and } \\
\text { Khomwan }\end{array}$} & BS37 & CFRP & 37 & 25.5 & 160 & 1.4 & 270 \\
\hline & BS53 & CFRP & 53 & 29.2 & 160 & 1.4 & 240 \\
\hline \multirow{10}{*}{ Boshetto et al. ${ }^{19}$} & $2 \mathrm{C} 2 \mathrm{a}$ & \multirow{10}{*}{ CFRP } & \multirow{5}{*}{58} & \multirow{5}{*}{$36^{* *}$} & 390 & 0.33 & 112 \\
\hline & $2 \mathrm{C} 1 \mathrm{a}$ & & & & 230 & 0.33 & 85 \\
\hline & $2 \mathrm{C} 2 \mathrm{c}$ & & & & 390 & 0.33 & 115 \\
\hline & $3 \mathrm{C} 2 \mathrm{a}$ & & & & 390 & 0.495 & 115 \\
\hline & $1 \mathrm{C} 1 \mathrm{~b}$ & & & & 230 & .165 & 80 \\
\hline & $2 \mathrm{C} 2 \mathrm{~d}$ & & 40 & 29.9 & 390 & 0.33 & 130 \\
\hline & $1 \mathrm{C} 2 \mathrm{c}$ & & \multirow{4}{*}{58} & \multirow{4}{*}{$36^{* *}$} & 390 & .165 & 95 \\
\hline & $3 \mathrm{C} 2 \mathrm{~b}$ & & & & 390 & 0.495 & 130 \\
\hline & $3 \mathrm{Cla}$ & & & & 230 & 0.495 & 115 \\
\hline & $3 \mathrm{C} 1 \mathrm{~b}$ & & & & 230 & 0.495 & 106 \\
\hline \multirow{4}{*}{ Iwashita et al. $^{20}$} & CS- 1 & \multirow{4}{*}{ PBO* FRP } & \multirow{4}{*}{36.8} & \multirow{4}{*}{30} & \multirow{4}{*}{235} & \multirow{4}{*}{0.128} & 130 \\
\hline & $\mathrm{CS}-2$ & & & & & & 125 \\
\hline & CS-3 & & & & & & 95 \\
\hline & CF-20-1 & & & & & & 120 \\
\hline \multirow{4}{*}{ Yang et al. ${ }^{21}$} & D21-20 & & \multirow{2}{*}{21} & 7 & & & 204 \\
\hline & D21-25 & & & 21.7 & & & 204 \\
\hline & D28-20 & CFRP & 20 & 25 & 173 & 1.3 & 196 \\
\hline & $\mathrm{D} 28-25$ & & 28 & 25 & & & 196 \\
\hline
\end{tabular}

*Poly-p-phenylene-BenzobiOxazole.

${ }^{* *} E_{c}$ is estimated according to $\mathrm{ACI}^{22}$ as $E_{c}=4730 \sqrt{f_{c}{ }^{\prime}}$ 


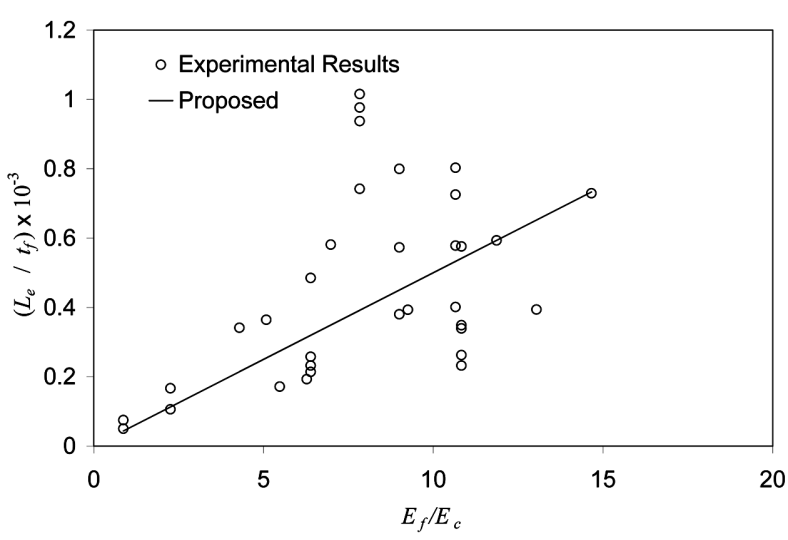

(a)

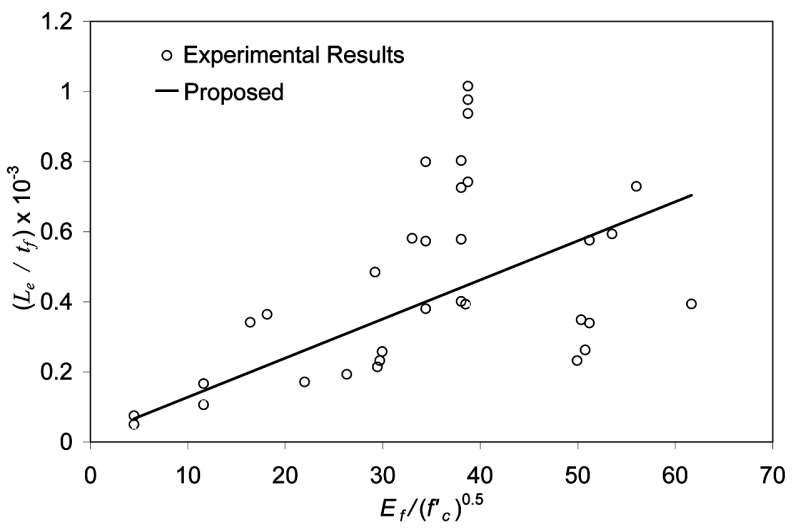

(b)

Fig. 3 Relationship between the effective bond strength and the affecting parameters such as FRP thickness, elastic modulus of concrete and FRP, and concrete strength.

mine the relationship between the EBL and the above mentioned parameters. When normalized by the FRP thickness, the EBL is presented as a function of the dimensionless ratio of the elastic modulus of the FRP to that of the concrete (Fig. 3(a)). The best fit curve of a linear correlation is expressed as:

$$
L_{e}=\frac{t_{f}}{20}\left(\frac{E_{f}}{E_{c}}\right)
$$

where $L_{e}$ : effective bond length (mm), $t_{f}$ : thickness of FRP (mm), $E_{f}$ : elastic modulus of FRP $(\mathrm{MPa})$, and $E_{c}$ : elastic modulus of concrete.

This relationship takes into account the stiffness of the FRP (i.e. thickness and elastic modulus of FRP) and the elastic modulus of the concrete. However, the most measured property of concrete is the concrete strength, not the elastic modulus. Thus, a relationship between the EBL and the concrete strength was also obtained as shown in Fig. 3(b), which can be expressed as:

$$
L_{e}=0.012 t_{f}\left(\frac{E_{f}}{\sqrt{f_{c}^{\prime}}}\right)
$$

where $f_{c}{ }^{\prime}$ is the concrete strength (MPa).

As it can be observed, these two equations are linear with respect to the FRP stiffness (i.e. thickness and elastic modulus of FRP). An attempt was made to try to have an equation expressing the EBL as function of a root square of the stiffness similar to that presented in many codes ${ }^{4-8}$, but the fitting was unsuitable.

The disadvantage of the two equations is the fact that they do not include all the depending parameters such as epoxy characteristics and bonding surface roughness, which is out of the scope of this study.

The advantage of these two equations is their simplicity for a practical use, as proposed by other codes. ${ }^{1-8}$ But contrary to the equations presented by the American ACI code ${ }^{1}$ and the Canadian CSA code ${ }^{3}$, it can be clearly shown from the proposed relationships that the EBL increases with an increase in FRP stiffness. Therefore, the equations of these codes showing an opposite trend should be revised.

\section{Conclusions}

Premature failure of concrete structures strengthened with externally bonded FRP due to debonding is an important problem that needs to be resolved for ensuring this emerging technology. In order to account for debonding problems, determination of the effective bond length is necessary. However, the effective bond lengths calculated by the equations adopted in the current codes/ guidelines/specifications were found to be inconsistent. This is mainly due to the equations being developed based on limited experimental data. Thus, the experimental data available in the literature were collected and analyzed in this study, which showed that the EBL is proportional to the stiffness of the FRP. Based on the collected data, simple but practical equations were proposed. Contrary to the American ACI code ${ }^{1}$ and the Canadian CSA $\mathrm{Code}^{2}$, the proposed equation (either 1 or 2 ) is proportional the FRP stiffness. Furthermore, the proposed equation is linear to the FRP stiffness and more simplified compared to the other remaining presented codes ${ }^{1-8}$.

\section{References}

1. ACI Committee 440, "Guide for the Design and Construction of Externally Bonded FRP Systems for Strengthening Concrete Structures," American Concrete Institute, ACI 440.2R-02, Farmington Hills, MI, USA, 2002.

2. ISIS Canada, "Strengthening Reinforced Concrete Structures with Externally-Bonded Fibre Reinforced Polymers (FRPs)", ISIS Design Manual No. 4, Intelligent Sensing for Innovative Structures, Winnipeg, Canada, 2001.

3. Canadian Standards Association, "Design and Construction of Building Components with Fiber-Reinforced Polymers," CSA S806-02, Rexdale, Ontario, Canada, 2002.

4. FIB Task Group 9.3, "Externally Bonded FRP Reinforcement for RC Structures," Technical Report, Fib Bulletin 14, CEB-FIP, Lausanne, Switzerland, 2001.

5. The Concrete Society, "Design Guidance for Strengthening Concrete Structures Using Fibre Composites Materials," Concrete Society, CS-TR-55-UK, Technical Report No. 55, $2^{\text {nd }}$ ed., Report of a Concrete Society Committee, Berkshire, UK, 2004

6. Italian Society Research Society, "Instructions for the Design, Execution and Control of Strengthening Measures through Fibre-reinforced Composites," CNR-DT 200/04, Rome, Italy, 2004.

7. Eurocode 8-3, "Design of Structures for Earthquake Resis- 
tance; Part 3: Assessment and Retrofitting of Buildings," European Standard, EN 1998-3, Brussels, Belgium, 2004.

8. CIDAR, "Design Guideline for RC Structures Retrofitted with FRP and Metal Plates: Beams and Slabs," Draft 3, Submitted to Standards Australia, CIDAR/CBIR, Australia, 2006.

9. Maeda, T., Asano Y., Sato T., Ueda T., and Kakuta Y., “A Study on Bond Mechanism of Carbon Sheet," Proceedings of the Third International Symposium (FRPRCS-3), Non-metallic (FRP) Reinforcement for Concrete Structures, Sapporo, Japan, Vol. 1, 1997, pp. 279 286.

10. Neubauer, U., Rostásy, F.S., "Design Aspects of Concrete Structures Strengthened with Externally Bonded CFRP-plates," Proceeding of the Seventh International Conference on Structural Faults and Repair, ECS Pub., Edinburgh, Scotland, Vol. 2, 1997, pp. 109 118.

11. Chen, J.F., Teng, J.G., "Anchorage Strength Models for FRP and Steel Plates Bonded to Concrete," ASCE Journal of Structural Engineering, Vol. 127, No.7, 2001, pp. 784 791.

12. Ueda, T., Dai, J.G., "Interface Bond between FRP Sheets and Concrete Substrates: Properties, Numerical Modeling, and Roles in Member Behaviour," Progress in Structural Engineering and Materials, Vol. 7, No. 1, 2005, pp. 27 43.

13. Ueda, T., Dai, J.G., "New Shear Bond Model for FRPconcrete Interface - from Modeling to Application," Proceedings of the Second International Conference on FRP Composites in Civil Engineering, CICE 2004, Adelaide, Australia, 2004, pp. 69 81.

14. Sato, Y., Kimura, K., Kobatake, Y., "Bond Behavior between CFRP Sheet and Concrete (Part 1)," Journal of Structure and Construction Engineering of AIJ, Japan; Vol. 500, 1997, pp. 75 82. (in Japanese).
15. Bizandavyi, L., Naele, K.W., "Transfer Lengths and Bond Strengths for Composites Bonded to Concrete," ASCE Journal of Composites and Construction, Vol. 3, No. 4, 1999, pp. 153 160.

16. De Lorenzis, L., Miller, B., Nanni, A., "Bond of Fiber-reinforced Polymer Laminates to Concrete," ACI Material Journal, Vol. 98, No. 3, 2001, pp. 256 264.

17. Nakaba, L., Kanakubo, T., Furuta, T., Yoshizawa, H., "Bond Behavior between Fiber-Reinforced Polymer Laminates and Concrete," ACI Structural Journal, Vol. 98, No. 3, 2001, pp. 359 367.

18. Foster, S. J. and Khomwan, N., "Determination of Bond Stress Versus Slip for Externally Bonded FRP from Standardized Bond Strength Tests," Proceeding of the International Symposium on Bond behavior of FRP in Structures, Hong Kong, 2005, pp. 85 90.

19. Boschetto, G., Pellegrino, C., Tinazzi, D., and Modena, C., "Bond Behaviour between FRP Sheets and Concrete: an Experimental Study" Proceeding of the Second International Congress, FIB, Naples, Italy 2006, CD-Rom.

20. Iwashita, K., Wu, Z., Ishikiwa, T., Hamagushi, Y., and Suzuki, T., "Bonding and Debonding Behavior of FRP Sheets under Fatigue Loading," Advances in Composites Materials, Vol. 16, No. 1, 2007, pp. 31 44.

21. Yang, D. S., Hong, S. N., and Park, S. K., "Experimental Observation on Bond-Slip Behavior between Concrete and CFRP Plate," International Journal of Concrete Structures and Materials, Vol. 1, No. 1, 2007, pp. 37 43.

22. ACI 318-05, Building Code Requirements for Structural Concrete (318-05) Band Commentary (318R-05), American Concrete Institute (ACI), Farmington Hills, MI, USA; 2005. 